\title{
Exploring factors affecting owners' trust of contractors in construction projects: a case of China
}

\author{
Shuangliang Tai, , Chengshuang Sun and Shoujian Zhang
}

\begin{abstract}
Background: It has been found that a low level of trust among members of a construction project team leads to poor performance in China. Many researchers have described the challenges, consequently advocating partnering as an attractive approach for more valuable cooperation. Because substantial investments have been poured into construction projects since the year 2000, trust research will improve the performance of construction projects and will be meaningful to the Chinese construction industry.

Purpose: The purpose of this paper is to investigate the attributes affecting owners'trust of contractors, to understand the potential properties of these factors, and to rank the factors in order of importance.

Results: Twenty-four attributes are identified from a literature review. Supported by qualitative reviews, a questionnaire is conducted to obtain relevant data, and 168 valid responses are obtained for data analysis. Principal component analysis (PCA) is employed to find the factor structure of the identified trust attributes. By the method of PCA, the attributes are extracted into eight factors, including interaction history, information sharing and communication, contract and institution, relation-specific investment, reputation, integrity, competence, and opportunistic behaviour. Conclusions: The value and originality of this paper are embodied in using PCA to understand the various attribute groupings and to illuminate trust impact factors in the Chinese context. When they understand the critical factors affecting trust better, owners and contractors can devise more appropriate strategies to improve performance.
\end{abstract}

Keywords: China, Trust attributes, Construction projects, PCA

\section{Background}

Many studies have identified the importance of trust in construction projects (Wong et al. 2000, 2008; Pinto et al. 2009; Cheung et al. 2011). However, the construction industry has a poor record of trust among construction project team members due to uncertainties and fragmentations of the construction process (Karlsen et al. 2008). Since the middle of the 1990s, the construction industry has been strongly criticised by professionals for its poor performance and non-cooperative working atmosphere that is characterised by mistrust and conflict. Many studies have described the challenges of construction

*Correspondence: taishlhit@hit.edu.cn

School of Civil Engineering, Harbin Institute of Technology, Harbin 150001, China projects, thus advocating partnering as an attractive approach for more valuable cooperation ( $\mathrm{Ng}$ et al. 2002; Bayliss et al. 2004; Cheung et al. 2012). One of the preconditions for the success of construction partnering is to build and develop trust among project team members. Trust and commitment is a critical factor for success of construction partnering (Cheung et al. 2003).

The construction industry represents one pillar in China's national economy. However, construction projects in China suffer from cost overruns and delays frequently. This poor performance arises in part from a lack of trust between owners and contractors (Yun and Jiang 2010). In fact, distrust and suspicion between the two are very common during the construction stage of projects in China. Lack of trust leads to poor communications and an adversarial relationship. To some extent, owners and 
contractors play a zero-sum game in China (Yang and Shuai 2011). However, professionals are making every effort to improve the performance of China's construction industry, and much attention has been given to trust among construction project team members both in practical and academic circles (Jiang et al. 2011).

Although much has been learned on this topic, little can be found about the factors affecting owners' trust of contractors in China, the two most important players in the construction project team. Trust between these two parties is crucial to the success of the construction project team. In this regard, it is critical to explore the relative importance and groupings of the factors for trust in construction projects within the Chinese context. The goals of the paper are to investigate the influence factors affecting owners' trust of contractors, to explore the potential properties of the factors, and to rank these factors in order of importance in China. An exploratory approach was adopted for this investigation. First, the list of attributes that influence trust was obtained by a literature review. Then, a questionnaire survey was conducted to collect quantitative data from owners using the attributes. The data collected was analyzed by PCA, which was employed to find the trust impact factor structure among the identified attributes and to get their groups. If they understand the critical factors affecting trust better, owners and contractors can formulate more appropriate strategies.

\section{An overview of trust and trust factors in construction}

There are three parts in this section. Firstly, concepts of trust in the literature are summarised, and trust between owners and contractors in this paper is defined. Secondly, sources of trust are identified. Lastly, the attributes affecting owners' trust of contractors are drawn from literature.

\section{Concept of trust}

Trust is widely discussed in many disciplines from different perspectives. Many concepts of trust have been introduced in the literature. Sabel (1993) proposed that "trust is the mutual confidence that no party to an exchange will exploit another's vulnerabilities". Rousseau et al. (1998) defined trust as "a psychological state comprising the intention to accept vulnerability based upon positive expectations of the intentions or behaviour of another". From the definition, trust is a state of mind that may lead to trusting intentions and behaviours. According to Nooteboom et al. (1997), trust is defined as "an expectation that people will not fail us, or the neglect or lack of awareness of the possibility of failure, even if there are perceived opportunities and incentives for it".
We can extract three common elements of trust from the definitions. The first trust element is uncertainty about the future. The second involves vulnerability, that is, the risk of loss. The third involves control: trust is placed in another who is not under one's control.

Trust concerns trusting intentions and trusting beliefs. A trusting intention implies a willingness to become vulnerable to another in a risky situation, while a trusting belief is the expectation that one will not be harmed by another in the risky situation (McKnight et al. 2002). Both factors are affected by one's own inclination to trust. Therefore, a distinction can be made between trustworthiness on the part of the trustee, and trust on the side of the trustor (McEvily et al. 2003).

As Gambetta (1998) observed, "trust is related to the limits of our capacity ever to achieve full knowledge of others, their responses and their motives to endogenous as well as exogenous changes". Therefore, many researchers have connected trust with risk (Nooteboom et al. 1997; Das and Teng 1998).

In the construction industry, owners lead the relationship with contractors. Therefore, trust in this paper is defined as an expectation of owners that the contractors will not conduct opportunistic behaviours, even when facing opportunities for get short-term gains by doing so (Laan et al. 2011).

\section{Sources of trust}

Because trust is defined as an expectation that a contractor will not fail an owner, we can question whether the contractor who is trusted has the capability to meet the expectation. This aspect of trust is called competence trust in the literature. It shows the level of trust one has in the managerial, organisational, and technical competences of the trustee (Nooteboom et al. 1997).

Another question is whether the contractor intends to use their capability to meet to the owner's expectations (Laan et al. 2011). This aspect of trust is the intentional aspect of trust. It refers to the intentions of the contractor towards the relationship. Intentional trust can be divided into trust in benevolence and trust in dedication, where benevolence represents the willingness to positively treat the owner under unforeseen circumstances and dedication represents the willingness to employ one's capabilities in the relationship (McAllister 1995).

Researchers in economics argue that trust comes from rational calculation, emphasising the extrinsic value of trust. However, researchers in psychology argue that trust comes from a social orientation towards other people, emphasising the intrinsic value of trust (e.g., Rousseau et al. 1998; Nooteboom et al. 1997). Nooteboom et al. (1997) assumed that trust has both rational reasons 
and psychological causes. The rational reasons for trust are based on the trustee's trustworthiness, while its psychological causes are effects, routine, the neglect of relational risk, etc. (Laan et al. 2011).

Therefore, competence and the intentions of the contractor are primary sources of trust between the contractor and the owner.

\section{Attributes affecting trust in construction}

The attributes affecting trust in a construction project team have been studied by many researchers worldwide. To identify as many of the publications about trust research in construction projects as possible and provide a comprehensive review on the subject, Google Scholar, EI Compendex, and Web of Science were searched using the keywords "trust", "construction project", or "construction industry". In total, 45 publications on trust in construction were identified for further analysis. The publications consist of journals papers, conference papers, theses, and some chapters in books. Sixteen of the publications were in Chinese.

These publications were reviewed to theoretically derive trust attributes in construction projects. The literature review indicated that many attributes had been identified as important for trust in construction projects. Based on the literature review, twenty-four trust attributes were identified, see Table 1.

\section{Methods}

In this study, a questionnaire survey was employed to collect quantitative data from owners. The methods of questionnaire is frequently employed by researchers to collect information about opinions and attitudes. Therefore, the method is suitable for trust research in this paper.

The target participants that were selected are owners since they lead the relationship with contractors. The questionnaire consists of two parts. Part I includes the profile of the participants, and Part II includes scales to measure the influence of 24 attributes on trust (as shown in Additional file 1). Some of the preliminary measurements are adapted from literature in English and translated into Chinese. The other measurements are from field interviews or literature in Chinese. Next, the preliminary measurements were modified by experienced consulting professionals and academics so that they were accurate, concise and clear.

The questionnaire was sent to the targeted participants by e-mail through the China Construction Industry Association (CCIA). For each of the 24 attributes, the participants were asked to state whether they agreed that the attribute has a high impact on trust in construction projects using a 5 -point Likert scale $(1=$ Strongly Disagree and $5=$ Strongly Agree).
PCA was employed to find groupings of the 24 identified variables and to investigate the potential characteristics. The goal of PCA is to find the crucial information from the data and to show the information as a set of new orthogonal variables, the principal components (Abdi and Williams 2010). Normally, there are fewer principal components than original variables. The principal components obtained are ranked according to the variance explained. The independence of the principal components is assured if the data set is jointly normally distributed. Cronbach's reliability test is used to determine the reliability of the attributes (Chiu and Lau 2015). Typically, a scale with a threshold value of .70 is regarded as having acceptable internal consistency (Wai et al. 2013).

To understand properties of identified factors better, semi-structured interviews with questions about trust were conducted with experienced practitioners.

\section{Results}

Introduction to the survey

We conducted the questionnaire survey from December 2012 to March 2013. All of the participants are project executives representing owners. One hundred and eighty-two replies out of 312 questionnaires were collected, and 168 replies were valid. The target construction projects were located in Changsha, Harbin, Guangzhou, Chongqing, and Beijing.

The profiles of participants are summarised in Table 2. The first two rows are information about the participants' firms, and the last two rows are information about the participants' current projects.

\section{Data tests}

Before the analysis, we have to make sure the reliability of the trust attributes and the adequacy of the sample size. SPSS 16.0 was employed for analysis in this study.

The results for the reliability of attributes are presented in Table 3 . The alpha value is .892 so that the reliability of the 24 attributes is enough for factor analysis.

Then, Kaiser-Meyer-Olkin (KMO) test and Bartlett's Test of Sphericity were conducted. The KMO is expressed as an index ranging from 0 to 1 . The literature suggests that the value of KMO should be greater than .70 for factor analysis (Stern 2009). Bartlett's Test of Sphericity checks the probability that the matrix is an identity matrix (Hair et al. 2006). The significance level of less than .05 is regarded as suitable. The value of KMO test is .741 and Bartlett's Test of Sphericity is also significant (see Table 4). Therefore, the data is suitable for PCA.

\section{Extraction of factors}

After all of the necessary requirements are satisfied, we conducted the factor analysis by PCA with varimax 
Table 1 Trust attributes from the literature (the following attributes have a high impact on trust based on literature review)

\begin{tabular}{|c|c|c|}
\hline Attributes & Frequency & Examples \\
\hline C1 competence & 15 & $\begin{array}{l}\text { Fong and Lung (2007), Kadefors (2004) and Cheung et al. } \\
\text { (2003) }\end{array}$ \\
\hline C2 honesty & 12 & Hartman (2015), Yeung et al. (2007) and Wang (2008) \\
\hline C3 problem solving mechanism & 6 & $\begin{array}{l}\text { Khalfan et al. (2007), Fong and Lung (2007) and Yeung } \\
\text { et al. (2007) }\end{array}$ \\
\hline C4 similarity & 5 & Nath and Mukherjee (2003) and Kadefors (2004) \\
\hline C5 information sharing & 9 & $\begin{array}{l}\text { Fong and Lung (2007), Hartman (2015) and Yeung et al. } \\
\text { (2007) }\end{array}$ \\
\hline C6 promise keeping & 8 & Wood et al. (2002) and Wong et al. (2010) \\
\hline C7 reputation & 8 & Fong and Lung (2007) and Yeung et al. (2007) \\
\hline C8 mutual respect & 4 & Yeung et al. (2007) and Cheung et al. (2003) \\
\hline C9 long-term cooperation & 3 & Yeung et al. (2007) and Smyth and Edkins (2007) \\
\hline C10 fairness & 4 & Wong and Cheung (2005) and Yeung et al. (2007) \\
\hline C11 effective communication & 11 & Wood et al. (2002) and Karlsen (2008) \\
\hline C12 frequent communication & 11 & $\begin{array}{l}\text { Fong and Lung (2007), Yeung et al. (2007) and Kadefors } \\
\text { (2004) }\end{array}$ \\
\hline C13 consistency between efforts and rewards & 8 & Wood et al. (2002) and Cheung et al. (2003) \\
\hline C14 behaviour reliability & 6 & Cheung et al. (2003) and Karlsen (2008) \\
\hline C15 confidence in the other & 5 & Smyth and Edkins (2007) and Atkinson et al. (2006) \\
\hline C16 completeness of contract & 10 & $\begin{array}{l}\text { Wong and Cheung (2005), Fong and Lung (2007) and } \\
\text { Yeung et al. (2007) }\end{array}$ \\
\hline C17 opportunistic behaviour & 4 & Jannadia et al. (2000) and Seymour and Rooke (1995) \\
\hline C18 supervision of the third party & 2 & Cheung et al. (2003) \\
\hline C19 goal achievement & 3 & Karlsen (2008) and Cheung et al. (2003) \\
\hline C20 interaction experience & 3 & Khalfan et al. (2007), Hartman (2015) \\
\hline C21 sense of social responsibility & 2 & Karlsen (2008) \\
\hline C22 good intentions & 4 & Karlsen (2008), Wong et al. (2010) \\
\hline C23 common goal & 5 & Khalfan et al. (2007), Karlsen (2008) \\
\hline C24 mutual interdependence & 4 & Khalfan et al. (2007), Wood et al. (2002) \\
\hline
\end{tabular}

Not all of the literature is listed in the table due to limited space

\section{Table 2 Profiles of the participants}

\begin{tabular}{llc}
\hline Profile & Category & Percentage \\
\hline Ownership of the firm & Public agencies & 35.1 \\
& State owned firms & 41.4 \\
& Private firms & 23.5 \\
Number of employees & $<500$ & 30.6 \\
& $500-2000$ & 47.8 \\
Type of project & More than 2000 & 21.6 \\
& Industrial buildings & 10.4 \\
& Commercial buildings & 7.8 \\
& Residential buildings & 43.8 \\
& Public buildings & 4.1 \\
& Infrastructure projects & 30.1 \\
Duration of project & Others & 3.8 \\
& $<1$ year & 8.1 \\
& 1-3 years & 69.6 \\
& More than 3 years & 22.3 \\
\hline
\end{tabular}

Table 3 Reliability Statistics for the 24 Attributes

\begin{tabular}{lll}
\hline Cronbach's alpha & $\begin{array}{l}\text { Cronbach's alpha based } \\
\text { on standardised items }\end{array}$ & No of items \\
\hline .892 & .896 & 24 \\
\hline
\end{tabular}

\section{Table 4 KMO and Bartlett tests}

\begin{tabular}{ll}
\hline Kaiser-Meyer-Olkin sampling adequacy & .741 \\
Bartlett's test of sphericity & \\
Approx. Chi square & 885.345 \\
$d f$ & 184 \\
Sig. & .000 \\
\hline
\end{tabular}

rotation. The rotation method is employed because it maximises the variance of the factor loadings by making the high loadings higher and the low loadings lower on 
each factor (Chiu and Lau 2015). The eigenvalue is used to measure the contributions of a variable to a principal components. Generally, extracted components with eigenvalues equal to or greater than 1.0 are regarded as being significant factors (Stern 2009).

A clear component structure exists if a variable has a significant factor loading (loading $>0.50$ ) on one component only (Spector 1992). The loading is employed to represent the impact of each variable on the individual component (Chiu and Lau 2015).

The rotated component matrix is shown in Table 5 . The accumulated variance of the components is shown in Table 6. We extracted eight components when we applied the rule of an eigenvalue greater than 1.0. The cumulative total variance accounted for $69.031 \%$ of the variation, which satisfies the criterion that factors should explain at least $50 \%$ of the variation. Table 5 shows that each attribute has significant loading on only one component and more than one variable load on each component. Therefore, all eight components can be kept for further analysis.
Followings are to explain the eight principal components extracted. Since the paper employs an exploratory approach involving many attributes, the explanation of the components is challenging. Another challenge is that the combinations of variables that load high on a component have patterns that are difficult to interpret. Therefore, the explanation of factors needs a certain amount of imagination and ingenuity (Wai et al. 2013). In the following section, based on the content and relationships among the variables, the labelling and explanation of each component is given.

\section{Discussions}

After a critical inspection of variables in the components, a proper name is given to each extracted factor. The eight factors are named as follows: the interaction history factor, the contracts and institutions factor, the information sharing and communications factor, the relation specific building factor, the competence factor, the reputation factor, the integrity factor, and the opportunistic behaviours factor.

Table 5 Rotated component matrix

\begin{tabular}{|c|c|c|c|c|c|c|c|c|}
\hline \multirow[t]{2}{*}{ Attributes } & \multicolumn{8}{|c|}{ Components } \\
\hline & 1 & 2 & 3 & 4 & 5 & 6 & 7 & 8 \\
\hline $\mathrm{C} 4$ & .785 & .045 & .106 & .176 & .186 & -.065 & .186 & -.082 \\
\hline $\mathrm{C9}$ & .687 & .074 & .106 & .193 & .035 & -.053 & .174 & -.056 \\
\hline $\mathrm{C} 20$ & .634 & .145 & .201 & .083 & .021 & .042 & .176 & .054 \\
\hline $\mathrm{C} 23$ & .625 & .065 & .173 & .186 & .079 & -.066 & .174 & -.073 \\
\hline $\mathrm{C} 3$ & .043 & .768 & .108 & .073 & .115 & -.022 & .187 & .067 \\
\hline $\mathrm{C} 10$ & .156 & .701 & .175 & .056 & .085 & .052 & .178 & .062 \\
\hline C16 & .175 & .624 & .193 & .098 & .137 & -.064 & .165 & .042 \\
\hline C18 & .105 & .619 & .078 & .073 & .124 & -.032 & .154 & .043 \\
\hline $\mathrm{C} 5$ & .175 & .024 & .723 & .067 & .184 & .196 & .043 & -.023 \\
\hline $\mathrm{C} 11$ & .067 & .093 & .703 & .162 & .046 & .187 & .101 & -.012 \\
\hline $\mathrm{C} 12$ & .087 & .165 & .693 & .201 & .189 & .054 & .123 & .012 \\
\hline $\mathrm{C} 8$ & .137 & .174 & .108 & .724 & .164 & .043 & .186 & -.043 \\
\hline $\mathrm{C} 22$ & .142 & -.176 & .065 & .701 & .045 & .097 & .054 & -.065 \\
\hline C24 & .107 & .153 & .063 & .684 & .143 & .042 & .195 & -.062 \\
\hline $\mathrm{C} 1$ & .164 & .197 & .064 & .095 & .653 & -.083 & .198 & -.045 \\
\hline C15 & -.021 & .065 & .045 & -.043 & .645 & .058 & .165 & -.073 \\
\hline C19 & .043 & .172 & .190 & .044 & .603 & -.106 & .045 & -.051 \\
\hline$C 7$ & .097 & -.043 & .021 & -.032 & .021 & .735 & .053 & .103 \\
\hline C13 & .056 & .074 & .043 & .164 & .075 & .611 & .198 & -.021 \\
\hline C21 & .032 & .179 & .154 & .011 & .102 & .606 & .221 & -.032 \\
\hline$C 2$ & .143 & -.105 & .092 & .235 & .194 & .083 & .802 & -.023 \\
\hline C6 & .052 & -.064 & -.076 & .014 & .107 & .074 & .734 & .078 \\
\hline $\mathrm{C} 14$ & .136 & .056 & .076 & .124 & .201 & .153 & .672 & .013 \\
\hline $\mathrm{C} 17$ & -.032 & .012 & -.032 & -.065 & -.054 & .154 & -.021 & .813 \\
\hline
\end{tabular}


Table 6 Accumulated variance explained by the components

\begin{tabular}{lll}
\hline Accumulated variance & & \\
\hline Component & \% of variance & Cumulative \% \\
\hline 1 & 16.924 & 16.924 \\
2 & 10.429 & 27.353 \\
3 & 8.713 & 36.066 \\
4 & 7.536 & 43.602 \\
5 & 7.177 & 50.779 \\
6 & 6.901 & 57.681 \\
7 & 6.329 & 64.010 \\
8 & 5.021 & 69.031 \\
\hline
\end{tabular}

Based on the findings from the survey and the opinions from interviews, the meanings of the eight factors are explained as follows.

\section{Interaction history}

The first factor includes four variables, namely "longterm cooperation", "interaction experience", "similarity", and "common goals" (see Table 6). These four variables explain $16.924 \%$ of the variance. Based on the potential characteristics of these variables, we name the factor as "interaction history".

Because of the dynamic, challenging, and complex nature of construction projects, interaction history is very important. For instance, relational bonding is identified as one of the trust factors because it explains trust between organisations derived from repeated interactions over time (Kadefors 2004).

The Chinese construction industry has blossomed since the year of 2000, which has created many contracting opportunities in construction market. Therefore, behaving trustworthy in past projects provides more opportunities for future projects.

The results from semi-structured interview also confirm the findings, and most of the participants noted that interaction history is very significant, especially longterm cooperation. Long-term interaction experience can significantly reduce uncertainties in terms of the other party's behaviours and thus improve trust.

\section{Contracts and institutions}

From Table 6, factor 2 explains $10.429 \%$ of the total variance. The factor includes "fairness", "mechanism for solving problems", "third party supervision", and "completeness of the contract". We note that these variables concern the problem solving system, the rights and obligation allocation system, and third party supervision. It is straightforward to label this factor as "contracts and institutions factor".
A contract with rigorous and comprehensive terms, a fair allocation of risks, an effective dispute resolution mechanism, and reliable supervision by independent agencies, is an institutional guarantee that protects the owners' interests. Therefore, the contracts and institutions factor plays an important role in trust. Cheung et al. (2003) found that a clearly defined contract brings comfort and confidence to the owner and the contractor, which can promote trust building process. In addition, Wong and Cheung (2005) noted that problemsolving ability is a critical attribute for the development of trust. If a conflict is resolved friendly, trust will be built.

This factor is confirmed by the interviews. Some interviewees feel safer and more likely to trust the contractors if their interests are protected by a good contract and institutional arrangements.

\section{Information sharing and communication}

Factor 3 consists of three variables, information sharing, frequent communication and effective communication, which account for $8.713 \%$ of the total variance. This factor is labelled "information sharing and communication". By exchanging of information and reducing misunderstandings, communication enables the parties to recognise mutual benefits. Information sharing can signal the willingness of a partner to be transparent, which is a key attribute of trustworthiness in a relationship (Wong and Cheung 2005).

The importance of frequent and effective communication and information sharing to increasing trust levels was confirmed by Wong and Cheung (2005). If clear and accurate information is disseminated in a timely manner, uncertainty will be reduced, thereby reducing misunderstand and enabling partners to work better together, finally improving the trust.

\section{Relation-specific investments}

Factor 4 includes "good intentions", "mutual respect", and "mutual interdependence", which account for $7.536 \%$ of the total variance (see Table 6). Good intentions mean that one party cares about the interests of the other party. Mutual respect means that a party treats the other equally and respectfully. Mutual interdependence means that both sides need to maintain their relationship.

Heide and John (1988) argued that mutual interdependence between enterprises comes from a "relation-specific investment" in maintaining cooperation, including investment in fixed assets, training and databases. Gundlach et al. (1995) argued that relation-specific investment is actually a type of attitudinal commitment reflecting the willingness to maintain cooperative relations and mutual recognition. A typical feature of a relation-specific 
investment is high sunk costs. If the relationship is broken, it is difficult to recover its value.

To some extent, mutual respect, good intentions and mutual interdependence are the result of a relation specific investment. Therefore, this factor is called relation specific investments.

\section{Competence}

Factor 5 consists of three variables: competence, confidence in the other, and goal achievement, which account for $7.177 \%$ of the total variance (see Table 6). The competence of contractors means that they have the technological and managerial skills to complete the project strictly according to the contract. The literature shows that the competence of a trustee is a precondition of trust. When the owner perceives the contractor's competence, it engenders confidence in the contractor. Higher competence means a greater likelihood of achieving the project goals. These three attributes are closely related to competence, so the factor is called competence.

\section{Reputation}

Factor 6 consists of "consistency between efforts and rewards", "reputation", and "sense of social responsibility", which account for $6.901 \%$ of the total variance. Reputation is an opinion about a contractor that is typically the result of a social evaluation based on a set of criteria. Reputation is difficult to build but is easy to destroy. A reputable contractor always tends to behave ethically and in a trustworthy manner. If a contractor has high social responsibility, he cares about the interests and welfare of the public. Therefore, this factor is called reputation.

\section{Integrity}

Factor 7 consists of three variables: "honesty", "promise keeping", and "behaviour reliability", which account $6.329 \%$ of the total variance. The factor is easy to interpret. If contractors always match their word with their deeds, they will be considered to be trustworthy.

\section{Opportunistic behaviours}

Factor 8 includes only one variable: "opportunistic behaviour". Opportunistic behaviour means that a contractor takes advantage of the owner's weaknesses to improperly benefit. Obviously, opportunistic behaviour harms trust.

These factors can be classified into three different categories. Reputation factor, competence factor, promisekeeping factor, and opportunistic behaviours factor are attributes of the contractor. These attributes represent the premise and preconditions for establishing trust. Information sharing and communication factor, interaction history factor and relation-specific investment factor involve both parties and belong to the relational dimension. They are methods and channels for maintaining and improving trust. The contract and institution factor is an institutional aspect that guarantees trust establishment and maintenance.

\section{Conclusions}

Trust between the owner and the contractor is currently an important concern in China. The poor performance of many construction projects has brought attention from construction professionals to know the key factors affecting trust. Taking a lead from previous studies, twenty-four attributes that affect trust are identified in this study, and the method of PCA is employed to obtain factor structure of the trust attributes. The 24 trust attributes are extracted into eight factors, including information sharing and communication, interaction history, contracts and institutions, competence, relationspecific investment, reputation, integrity, and opportunistic behaviours. These factors form basis for improving owners' trust of contractors in China. The value and originality of this paper is to use PCA to group these various trust attributes and expound these eight trust factors for construction in China.

This paper has two contributions. Firstly, it is a contextdriven research that identifies trust factors. Second, by grouping these factor components, the findings provide implications that will assist owners and contractors to improve the trust between them. The factor component groupings represent the critical trust attributes, implying that these eight factors should be considered carefully. The enhanced understanding presented in the paper enables the development of methods and strategies for building trust.

However, this research has some limitations. In terms of its methodological approach, this paper is a exploratory and confirmatory research. In addition, a larger sample size would have provided a more robust factor analysis. Future research to explore exactly how these trust impact factors can be enacted is important for improving trust between owners and contractors.

\section{Additional file}

Additional file 1. Questionnaire on Trust Factors between Owners and Contractors in China.

\section{Authors' contributions}

TS designed the questionnaire, carried out the PCA analysis, and wrote the manuscript. SC interviewed the professionals, collected the data and modified the manuscript. ZS conceived the study, reviewed and edited the manuscript. All authors read and approved the final manuscript. 


\section{Acknowledgements}

The work described in this paper was supported by the Fundamental Research Funds for the Central Universities (Grant No. HIT.HSS.201204). Special gratitude is devoted to those industrial practitioners who have responded to and contributed their valuable input in completing the survey questionnaires in China.

\section{Competing interests}

The authors declare that they have no competing interests.

Received: 24 May 2016 Accepted: 26 September 2016

Published online: 13 October 2016

\section{References}

Abdi H, Williams LJ (2010) Principal component analysis. Wiley Interdiscip Rev Comput Stat 2:433-459

Atkinson R, Crawford L, Ward S (2006) Fundamental uncertainties in projects and the scope of project management. Int J Proj Manag 24(8):687-698

Bayliss R, Cheung S-O, Suen HC, Wong S-P (2004) Effective partnering tools in construction: a case study on MTRC TKE contract 604 in Hong Kong. Int J Proj Manag 22:253-263

Cheung S-O, Ng TST, Wong S-P, Suen HCH (2003) Behavioral aspects in construction partnering. Int J Proj Manag 21:333-343

Cheung SO, Wong WK, Yiu TW, Pang HY (2011) Developing a trust inventory for construction contracting. Int J Proj Manag 29:184-196

Cheung E, Chan AP, Lam PT, Chan DW, Ke Y (2012) A comparative study of critical success factors for public private partnerships (PPP) between Mainland China and the Hong Kong Special Administrative Region. Facilities 30:647-666

Chiu WYB, Lau HLE (2015) Quantity Surveyors' Perception of Cost Impact Factors in Hong Kong Civil Engineering Projects. J Constr Eng Proj Manag $5: 1-9$

Das TK, Teng B-S (1998) Between trust and control: developing confidence in partner cooperation in alliances. Acad Manag Rev 23:491-512

Fong PSW, Lung BWC (2007) Interorganizational teamwork in the construction industry. J Constr Eng Manag 133(2):157-168

Gambetta D (1998) Concatenations of mechanisms. In: Hedström P, Swedberg $\mathrm{R}$ (eds) Social mechanisms: an analytical approach to social theory. Cambridge University Press, Cambridge, pp 102-124

Gundlach GT, Mentzer JT (1995) The structure of commitment in exchange. J Mark 59(1):78-92

Hair JF, Tatham RL, Anderson RE, Black W (2006) Multivariate data analysis. Pearson Prentice Hall, Upper Saddle Rive

Hartman FT (2015) Ten commandments of better contracting: a practical guide to adding value to an enterprise through more effective smart contracting. American Society of Civil Engineers, Reston

Heide JB, John G (1988) The role of dependence balancing in safeguarding transaction-specific assets in conventional channels.J Mark 52(1):20-35

Jannadia MO, Assaf S, Bubshait AA, Naji A (2000) Contractual methods for dispute avoidance and resolution (DAR). Int J Proj Manag 18(1):41-49

Jiang W, Zhang Q, Le Y (2011) Occurrence and influence of trust in construction projects from the view of clients. J Eng Manag 25:13 (in Chinese)

Kadefors A (2004) Trust in project relationships -inside the black box. Int J Proj Manag 22:175-182

Karlsen JT (2008) Forming relationships with stakeholders in engineering projects. Eur J Ind Eng 2(1):35

Karlsen JT, Græe K, Massaoud MJ (2008) Building trust in project-stakeholder relationships. Balt J Manag 3:7-22
Khalfan MMA, Mcdermott P, Swan W (2007) Building trust in construction projects. Supply Chain Manag 12(6):385-391

Laan A, Noorderhaven N, Voordijk H, Dewulf G (2011) Building trust in construction partnering projects: an exploratory case-study. J Purch Supply Manag 17:98-108

McAllister DJ (1995) Affect-and cognition-based trust as foundations for interpersonal cooperation in organizations. Acad Manag J 38:24-59

McEvily B, Perrone V, Zaheer A (2003) Trust as an organizing principle. Organ Sci 14:91-103

McKnight DH, Choudhury V, Kacmar C (2002) Developing and validating trust measures for e-commerce: an integrative typology. Inf Syst Res 13:334-359

Nath P, Mukherjee A (2003) A model of trust in online relationship banking. Int J Bank Mark 21(1):5-15

Ng ST, Rose TM, Mak M, Chen SE (2002) Problematic issues associated with project partnering - the contractor perspective. Int J Proj Manag 20:437-449

Nooteboom B, Berger H, Noorderhaven NG (1997) Effects of trust and governance on relational risk. Acad Manag J 40:308-338

Pinto JK, Slevin DP, English B (2009) Trust in projects: an empirical assessment of owner/contractor relationships. Int J Proj Manag 27:638-648

Rousseau DM, Sitkin SB, Burt RS, Camerer C (1998) Not so different after all: a cross-discipline view of trust. Acad Manag Rev 23:393-404

Sabel CF (1993) Studied trust: building new forms of cooperation in a volatile economy. Hum Relat 46:1133-1170

Seymour D, Rooke J (1995) The culture of the industry and the culture of research. Constr Manag Econ 13(6):511-523

Smyth H, Edkins A (2007) Relationship management in the management of pfi/ppp projects in the UK. Int J Proj Manag 25(3):232-240

Spector PE (1992) Summated rating scale construction: an introduction. Sage, Beverley Hills

Stern LD (2009) A visual approach to SPSS for windows: a guide to SPSS 17.0. Allyn \& Bacon Inc, Boston

Wai SH, Yusof AM, Ismail S, Ng CA (2013) Exploring success factors of social infrastructure projects in malaysia. Int Eng Bus Manag 5:2. doi:10.5772/55659

Wang DM (2008) Trust factors and trust building mechanics in engineering. Dissertation of Zhongnan University (in Chinese)

Wong PSP, Cheung SO (2005) Structural equation model of trust and partnering success. J Manag Eng 21:70-80

Wong E, Then D, Skitmore M (2000) Antecedents of trust in intra-organizational relationships within three Singapore public sector construction project management agencies. Constr Manag Econ 18:797-806

Wong ES, Then D, Skitmore M (2010) Antecedents of trust in intra-organizational relationships within three singapore public sector construction project management agencies. Constr Manag Econ 18(7):797-806

Wong WK, Cheung SO, Yiu TW, Pang HY (2008) A framework for trust in construction contracting. Int J Proj Manag 26:821-829

Wood G, Mcdermott P, Swan W (2002) The ethical benefits of trust-based partnering: the example of the construction industry. Bus Ethics A Eur Rev 11(1):4-13

Yang L, Shuai C (2011) Dimensional analysis of trust between enterprises in the project. Constr Econ 32:6 (in Chinese)

Yeung JFY, Chan APC, Chan DWM (2007) The definition of alliancing in construction as a Wittgenstein family-resemblance concept. Int J Proj Manag 25(3):219-231

Yun L, Jiang W-P (2010) Occurrence mechanism of trust in construction projects. J Eng Manag 3:016 (in Chinese) 